\title{
ABORDAGEM CIRÚRGICA NO TRAUMA GRAVE DE FACE
}

Thiago Hoffmann JONASSON, Leonardo Silva BENATO, Kelston Ulbricht GOMES, Maurício ROMANOWSKI, João Luiz CARLINI

O objetivo desse estudo foi demonstrar a eficiência da utilização do acesso bicoronal no trauma severo craniofacial, mais especificamente em fraturas de terço médio da face, ou naso-órbito-etmoidais. O acesso bicoronal, quando comparado com outras técnicas, proporciona ampla exposição das estruturas acometidas. Será apresentado um caso clínico em que se utilizou o acesso bicoronal em um paciente vítima de acidente motociclístico, com fraturas do tipo Le Fort III unilateral, naso-órbito-etmoidal, fratura de parede anterior e posterior de seio frontal, fratura de zigoma e fratura mandibular, tratado com acesso bicoronal, infra-orbitário e intra-bucal. O caso foi tratado no Hospital Universitário Pedro Ernesto-UERJ, Rio de Janeiro. No período pósoperatório o paciente foi avaliado através de exames tomográficos, radiografias de face e exame clínico. O paciente apresentou-se com resultados, tanto estéticos como funcionais, satisfatórios, considerando a gravidade do trauma. Conclui-se que a abordagem e o tratamento de pacientes vítimas de fraturas graves do terço médio de face devem ser feitos através de uma exposição cirúrgica ampla da região acometida. Os resultados estético-funcionais tornamse muito mais previsíveis, pois é possível uma visualização direta das fraturas e, a redução é feita de forma adequada com material de fixação interna rígida, devidamente aplicada.

Palavras Chaves: Cirurgia; Fraturas Cranianas; Traumatismo. 